\title{
Novas centrais sindicais: desafios e limites na contemporaneidade
}

\author{
Thamires Cristina da Silva*
}

\begin{abstract}
Resumo: Este artigo propõe a discussão sobre a redefinição do papel das centrais sindicais na sociedade brasileira com base na compreensão do sistema sindical contemporâneo, o qual incorpora características de continuísmo e de inovação observadas nas novas centrais sindicais que emergiram na última década. O campo de observação privilegia variações recentes da trajetória sindicalista, após o impacto da crise dos sindicatos na década de 1990, a qual despontou profundas mudanças nas relações entre o capital e o trabalho. Neste trabalho, as novas centrais sindicais representam uma ruptura com a força social assimilada por centrais sindicais tradicionais em outro referencial temporal, e projetam para o futuro da sociedade capitalista delineações institucionais que efetivam o diálogo das regulações complexas do trabalho. De forma analítica, este trabalho pretende apontar diferentes visões de sindicalismo difundido pelos representantes das novas centrais sindicais e identificar novas formatações do corporativismo sindical no Governo Lula, a fim de questionar suas práticas e interesses, e confrontá-las com a atuação de centrais sindicais tradicionais, isso por meio do material de pesquisa de campo. Esta plataforma de discussão traz uma perspectiva atualizada sobre as novas construções do sindicalismo.
\end{abstract}

Palavras-chave: novo sindicalismo, centrais sindicais, Governo Lula, corporativismo, capitalismo sindical.

\section{Panorama do sindicalismo contemporâneo}

O cenário que pretendemos construir com esta pesquisa conforma um paralelo entre as novas centrais sindicais, fundadas no início do século XXI, e as centrais sindicais tradicionais surgidas após o fenômeno sindical que deu origem à denominação Novo Sindicalismo ${ }^{1}$. Dessa forma, buscamos alcançar múltiplas leituras sobre a possibilidade de inovação no campo do sindicalismo a partir do surgimento das novas centrais sindicais. Uma delas refere-se à possibilidade de transformação da estrutura sindical tradicional, ou apenas a reprodução continuada do que já está determinado na agenda das práticas sindicais cotidianas.

\footnotetext{
${ }^{*}$ Graduanda em Ciências Sociais - FESPSP.

10 termo "Novo Sindicalismo" expressou o momento de ascensão do movimento sindical no cenário político nacional iniciado com as mobilizações dos sindicalistas metalúrgicos no ABC e Diadema, região mais industrializada da capital paulista. A erupção de greves iniciadas em 1978 anunciou a retomada dos trabalhadores na cena pública no momento de redemocratização do país. Assim, o Novo Sindicalismo resignificou a participação dos trabalhadores na cena nacional e ofereceu novos instrumentos de luta para inovar a ação sindical desse período, potencializada com a criação da CUT em 1983 (RoDRIGUES, 1999).
} 
A comparação entre o continuísmo e a inovação reflete o posicionamento das novas representações do sindicalismo ante os desafios colocados no nosso tempo, permitindo uma relação aproximada entre contextos que convocam o passado para a realização dos projetos sindicais atuais. Para tanto, a metodologia desta pesquisa privilegiou a transmissão de falas e sintonias com o presente que as novas centrais sindicais estabelecem no cenário social. Assim, podemos suspender por alguns instantes o distanciamento temporal de fundação das centrais sindicais tradicionais como CUT (Central Única dos Trabalhadores) e Força Sindical (FS) das novas centrais sindicais UGT (União Geral dos Trabalhadores), Conlutas (Coordenação Geral de Lutas) e Intersindical. Foram realizadas três entrevistas com representantes das novas centrais cuja seleção partiu da relevância de suas atuações nas respectivas entidades. A CUT e a FS correspondem à categoria de centrais sindicais tradicionais - neste trabalho serão referenciadas com base em fontes secundárias - enquanto a UGT, Conlutas e Intersindical serão parte da expedição de campo realizada, com esforço de somar falas que configuram o sindicalismo na atualidade. Essas duas esferas (centrais sindicais tradicionais e novas centrais sindicais) correspondem ao referencial de análise deste trabalho, para identificar o atual percurso sindical praticado no Brasil e acompanhar mudanças e/ou repetições nas práticas sindicais promovidas pelos representantes entrevistados. As lacunas compostas pelo tempo evidenciadas no amplo terreno das proposições sindicais discursivas funcionam como método de despertar o passado para recriação imediata da ideia de futuro exposto nas falas dos sindicalistas. As entrevistas contribuem como recurso indispensável ao esforço teórico desta pesquisa e possibilitam uma interação entre os contextos particulares das experiências sindicais, vivenciadas pelos entrevistados.

O ideal de um mundo mais democrático, justo e inclusivo foi um dos capítulos protagonizados pelo movimento sindical brasileiro. As mobilizações promovidas no período de redemocratização destacaram o Novo Sindicalismo como promessa de um movimento popular inédito, engajado em lutas populares e mediador da participação ativa dos trabalhadores por melhores condições sociais. As transformações sucessivas no mundo do trabalho e a velocidade das mudanças econômicas sofridas em escala internacional - fatores que implicaram uma desestabili- 
zação da organização dos trabalhadores e um esforço para recriar o modelo corporativo adotado pelas centrais sindicais - modificaram os paradigmas do sindicalismo. Os dispositivos de representação sindical junto ao território de seu reconhecimento (dos trabalhadores e outras instituições formais) repousam no desafio de superar os moldes da estrutura e alavancar o encontro de interpretações distintas sobre a realidade social que se impõe na agenda dos sindicalistas.

O fenômeno da globalização e o advento de novas tecnologias engendraram um novo formato para o trabalho. 0 capitalismo flexível impulsionado pela reestruturação produtiva e a flexibilização das relações trabalhistas pulsaram uma carga de subjetividade no caráter dos indivíduos, criando um novo perfil de trabalhador estudado por Richard Sennett. Segundo suas análises, a perda de vínculos sociais duradouros, o esvaziamento da experiência como estímulo de narrativas acerca da vida, a integridade e a confiabilidade no próximo são fatores que participaram da noção de comunidade, mas foram minimizados na sociedade contemporânea (SENNETT, 2004). Esse processo exigiu uma readaptação das estratégias corporativas, cercando o indivíduo com novos dispositivos de regulação necessários para o desenvolvimento do neoliberalismo. A predominância desse perfil empresarial exigiu releituras atualizadas dos sindicatos sobre o comportamento dos trabalhadores nessa fase do capitalismo global, fator que, dentre outros, contribuiu para as mudanças de natureza reivindicatória do movimento sindical.

Na mesma corrente, Cornelius Castoriadis (1992) identificou o fenômeno da informatização como fator de esvaziamento de significados que contribuiu para a refração do tempo no espaço de interação e para o excessivo grau de individualismo. A expectativa otimista da substituição da produção automática por um espaço de criação fundamentado nas inovações tecnológicas foi reduzida, ao passo que a participação do "trabalhador flexibilizado" em sua base sindical levou à falência o prestígio dos instrumentos de representação que poderiam ser utilizados em seu benefício. Mais adiante, o cientista político Krishan Kumar (KumaR; Jungmann, 1997) estudou a concepção recorrente de pós-modernidade ${ }^{2}$ na atualidade, evi-

\footnotetext{
20 conceito de pós-modernidade para Kumar refere-se ao fluxo de mudanças sociais aleatórias, sem correspondência com uma trajetória continuada no tempo. 0 individualismo excedeu às práticas coletivas, determinando um caráter mutável nas conexões humanas com o mundo de interação institucional e de participação
} 
denciando a dissolução das teorias fixadas nas relações produtivas industriais por uma administração científica. As condições produtivas e a intensificação do consumo configuraram o painel institucional do trabalho, cuja influência recai em todos os raios de ação do indivíduo. As relações comerciais tornaram-se multilaterais e o trabalho internacionalizado, os empreendimentos ao consumo e de produção tecnológica determinaram outra forma de gerenciamento corporativo, que também influenciou políticas de instituições burocráticas do Estado. 0 alcance desse fenômeno resultou na mudança de contratações trabalhistas em função da rápida evolução da tecnologia e das novas categorias de emprego criadas, fator que contribuiu essencialmente para o abalo da estrutura sindical nos anos de 1990.

\section{Perspectiva histórica e a instituição sindicato}

Os traços da política institucional brasileira, reconfigurada em uma nova conjuntura, trouxeram diversas tendências para pensar os regimes contemporâneos de regulação sindical. A linearidade histórica do sindicalismo propõe interpretações que revelam uma marca do tempo nas práticas atuais das novas centrais, assim como as tradicionais centrais sindicais. Ambas as categorias, por natureza jurídica, sugerem a unicidade representativa, condensando no interior de seu organismo em níveis diferenciados uma pluralidade de sindicatos com interesses distintos, que ora pretendem expandir sua atuação dissociada ao Estado, ora buscam espaços sólidos para negociar seus interesses diretamente com empresários e com o governo. A escolha das direções políticas sindicais corresponde ao empreendimento das articulações corporativas implantadas no período do Estado Novo (1937-1945), responsável por modernizar as instituições de bases tradicionais no Brasil. Esse processo conduziu a um momento de intensa atividade legislativa sobre o campo das relações de capital e trabalho, denominado como o período de “controle sindical" de 1934 até 1945, durante o primeiro governo de Getúlio Vargas (RoDRIGUES, 1968, p. 11).

política. Assim temos a definição “O pós-modernismo é em essência a eclética mistura de qualquer tradição com a do passado imediato: é tanto uma continuação do modernismo quanto sua transcendência" (KumAR; JUNGMANN, 1997, p. 123). 
A forte influência governamental instaurou a legislação do trabalho baseada nos interesses do empresariado industrial, a fim de mobilizar o avanço econômico e introduzir o Brasil no circuito das relações econômicas modernas. A concessão das leis trabalhistas no formato da Consolidação das Leis do Trabalho (CLT) foi uma estratégia de união do Estado com o empresariado, no intuito de enfraquecer a organização sindical e permitir a implantação do capitalismo em pleno funcionamento com as condições de acumulação do mundo moderno. Os desdobramentos do processo de modernização brasileira reificaram uma memória na trajetória do sindicalismo, construindo uma identidade espelhada nas estruturas do Estado interposta nas ações das centrais sindicais.

A predominância da estrutura sindical corporativa admitiu adaptações às demandas sociais, mas não comprometeu a estrutura tradicional. 0 corporativis$\mathrm{mo}^{3}$, desse modo, explica uma das correntes políticas brasileira, com a tarefa de construir a malha das relações liberais modernas por meio da incorporação de valores burgueses na sociedade. Temos, então, uma relação ambígua de garantia de existência do sindicato, que, por um lado, necessita da regulação corporativa como mantenedora da estrutura e, por outro, necessita de atualizações permanentes quanto às mudanças no mercado de trabalho (NuNES, 2003).

Em contrapartida, a interpretação de Adalberto Cardoso (2003) lançou movimento ao consenso teórico de corporativismo brasileiro. O Estado tornou-se o centro de direito trabalhista e produziu um conflito de regulações institucionais, suspendendo o tipo corporativista e assumindo o modelo de relações de trabalho legislado. 0 corporativismo implantado pelo executivo "definia os sindicatos como parte do aparelho estatal e o direito sindical como parte do direito público, mas as relações de trabalho, isto é, o uso cotidiano do trabalho, era regulado, sobretudo, por instrumentos de direito privado, relativos a obrigações contratuais"4 (CARDoso,

\footnotetext{
${ }^{3}$ O corporativismo funciona como importante estratégia para vincular o trabalho ao Estado. Para Edson Nunes "[a]tualmente o corporativismo no Brasil é um mecanismo que serve ao propósito de absorver de forma antecipada o conflito político através [sic] da incorporação e da organização do trabalho" (NuNES, 2003, p. 36).

${ }^{4}$ Ao contrário de Edson Nunes - que interpreta a ordem corporativa como um aspecto político institucional adaptado ao tempo, junto com outras características tradicionais da política que mantém espaço para modificações dentro da lógica de modernizar com instrumentos de conservação - para Cardoso, no conceito de corporativismo difundido por teóricos do assunto não predominam as relações vigentes do trabalho. Ele corresponde enquanto importante ator para a Revolução de 1930 na primeira fase da Era Vargas, e muda de figura com os acontecimentos sociais decorridos no tempo (CARDOSo, 2003).
} 
2003, p. 121). 0 quadro normativo dos sindicatos determinou uma existência corporativa ao direito do trabalho, de forma que seria impossível avivar alguma manifestação sindical fora da estrutura do Estado. Assim, a garantia de bem-estar social ficou restrita às categorias de trabalho determinadas pelo governo mediante seu papel fundamental no desenvolvimento da economia nacional. 0 modelo rígido das normas da CLT perdeu uma importante fração da função de proteger o trabalhador, em decorrência da flexibilização contratual produzida por novas categorias de emprego surgidas no final do século XX. A nova configuração das relações de trabalho no Brasil promovida pela inovação tecnológica colocou a Justiça do Trabalho como o principal centro de mediação dos mecanismos de representação coletiva, como os sindicatos e as centrais sindicais. A debilidade desse processo de controle sindical foi potencializada pela crescente judicialização, utilizada como recurso principal para advogados dispostos a aplicar infinitas interpretações aos processos trabalhistas individuais, e não à natureza coletiva do direito do trabalho baseado nas tensões produzidas entre as classes sociais.

Após a Constituição de 1988, o sindicalismo brasileiro passou pela fase de “concertação social”, responsável por criar estratégias de manutenção da sobrevivência sindical ante os impulsos do capital produtivo. 0 corporativismo passou por uma alteração adequada às novas alternativas do mercado global, ao passo que a estrutura sindical também sofreu adaptações em um terreno de incertezas instaurado. 0 Estado preservou a unicidade e desfez o controle tutelar sobre o sindicato, obrigando um rearranjo dos valores convencionais intrínsecos ao sindicalismo, flexibilizando também o trato com a regulação sindical. Esse processo implicou o enfraquecimento da CUT, que de oposição passou a colaborar com as regras do jogo econômico dominante (ALVES, 2000).

0 processo que culminou com a crise do trabalho alterou a zona de conforto das estratégias sindicais e deslocou seu eixo reivindicatório para proposições de difícil acesso aos trabalhadores, enfraquecendo seu discurso enquanto instrumento de comando da classe. A intensificação das trocas complexas originadas da globalização fez do termo "a nova questão social”, recorrido por José Ricardo Ramalho e Marco Aurélio Santana (2003), um destaque para a criação de outras categorias de entendimento com base na apropriação dos sentidos e nas práticas produzidas 
com a organização flexível dos mercados mundiais, que originou outras inúmeras condições de trabalho. As centrais sindicais alçam questões que ultrapassam as relações sindicais, para definir novos posicionamentos com outros setores da sociedade que mesclam uma constelação de interesses ${ }^{5}$.

\section{A transitoriedade das experiências das centrais sindicais tradicionais e das novas centrais sindicais}

Nesta parte do artigo avaliaremos o efeito do tempo na estrutura sindical, que contém em si contradições visualizadas no paralelo entre as centrais sindicais tradicionais e as novas centrais sindicais. Em vista disso, o ensaio sobre o sindicalismo e o equilíbrio de fatores de discordância com sua existência, portanto, da produção de valores no mundo de agora, gera uma inclinação para o tipo de politização dos atos sindicais. A central sindical é um órgão de representação unívoca, que agrupa uma pluralidade de sindicatos a fim de fortalecer sua atuação principalmente no campo trabalhista. Seu envolvimento com o neoliberalismo causou uma crescente vulnerabilidade dos trabalhadores pela ausência de uma entidade que poderia idealizar maior participação na distribuição de renda do país e convocar a prática constante de defesa de direitos trabalhistas no cotidiano.

Atualmente o Ministério do Trabalho e Emprego (MTE) possui em seu quadro de reconhecimento 18 centrais sindicais ${ }^{6}$. No quadro a seguir, podemos visualizar o coeficiente representativo das centrais sindicais com base em seus sindicatos de trabalhadores filiados:

\footnotetext{
${ }^{5}$ Este fator pode indicar um papel relevante às novas centrais sindicais por participarem do cenário já modificado pelas relações de trabalho, de forma que se contemple uma posição de vantagem em relação à mobilidade social atual. 0 conteúdo das modificações produtivas rebateu nas entidades sindicais e em outras instituições brasileiras, dependentes do Estado e de políticas de expansão econômica neoliberal.

${ }^{6}$ Por meio dos dados de aferição da representatividade das centrais sindicais em 2010 constatou-se: 38,23\% para CUT; $13,71 \%$ para FS; 7,55\% para CTB; 7,19\% para UGT; 6,69\% para NCST e 5,04\% para a CGTB. (Ministério do Trabalho e Emprego: http://www.mte.gov.br/central_sindical/default.asp).
} 


\begin{tabular}{|c|c|}
\hline CENTRAL SINDICAL & $\begin{array}{l}\text { ENTIDADES SINDICAIS } \\
\text { FILIADAS (em número) }\end{array}$ \\
\hline CUT (Central Única dos Trabalhadores) & 1.698 \\
\hline FS (Força Sindical) & 982 \\
\hline $\begin{array}{l}\text { NCST (Nova Central Sindical de Trabalhado- } \\
\text { res) }\end{array}$ & 680 \\
\hline UGT (União Geral dos Trabalhadores) & 559 \\
\hline $\begin{array}{l}\text { CTB (Central de Trabalhadores e Trabalha- } \\
\text { doras do Brasil) }\end{array}$ & 271 \\
\hline $\begin{array}{l}\text { CGTB (Central Geral dos Trabalhadores do } \\
\text { Brasil) }\end{array}$ & 244 \\
\hline CSP (Central Sindical de Profissionais) & 88 \\
\hline $\begin{array}{l}\text { CGT (Confederação Geral dos Trabalhado- } \\
\text { res) }\end{array}$ & 39 \\
\hline Associação Coordenação Nacional de Lutas & 39 \\
\hline $\begin{array}{l}\text { Associação Nacional dos Sindicatos Social } \\
\text { Democrata }\end{array}$ & 35 \\
\hline UST (União Sindical dos Trabalhadores) & 6 \\
\hline CAT (Central Autônoma de Trabalhadores) & 6 \\
\hline CNT (Central Nacional dos Trabalhadores) & 2 \\
\hline União Sindical Independente & 2 \\
\hline USB (União Sindical Brasileira) & 1 \\
\hline Polo Sindical da Região de Livramento & 1 \\
\hline $\begin{array}{l}\text { União Nacional Sindical - Unidade do Estado } \\
\text { de Minas Gerais }\end{array}$ & 1 \\
\hline $\begin{array}{l}\text { Intersindical da Orla Portuária do Espírito } \\
\text { Santo }\end{array}$ & 1 \\
\hline
\end{tabular}

Fonte de pesquisa: <http://sis.dieese.org.br/consulta_simples.php?central>.

As novas centrais compartilham da mesma realidade que se impõe para as centrais tradicionais e avolumam o pluralismo concorrencial existente entre elas. Mas a principal questão a ser levantada é a capacidade representativa que cada central possui para agregar à sua unidade as diversas entidades sindicais. Na ordem de classificação numérica, a CUT liderou a representatividade sindical, seguida da FS com 982 entidades filiadas. Já as novas centrais sindicais apresentaram uma discrepância representativa em relação ao cadastramento sindical do MTE. A UGT, por exemplo, ocupou a posição de 4o lugar, enquanto a Conlutas apresentou 39 entidades sindicais filiadas. Devemos a esses números um momento importante para as centrais sindicais: o de seu reconhecimento oficial na ordem jurídica brasi- 
leira7 . Com base no modelo de lei proposto pelo MTE, verificamos a existência de centrais sindicais com irrisória capacidade representativa da classe trabalhadora. No entanto, um fator legitimado pelo estatuto consolidou a participação de $10 \%$ na divisão da contribuição sindical para as centrais, dentro do montante que é absorvido entre confederações, federações, sindicato da categoria, e também para a "Conta Especial Emprego e Salário"8. Levando em conta os aspectos de reconhecimento das centrais sindicais, as condições legitimadas pelo poder executivo reiteraram o aparecimento de novas centrais agora beneficiadas com a nova lei. Nesse sentido, mesmo que as novas centrais se assemelhem, no que tange às práticas, às centrais sindicais tradicionais, o principal fator de incentivo empregado na atualidade vai além da capacidade representativa da entidade: os interesses estão circunscritos na divisão das arrecadações de impostos sindicais.

A metamorfose no mundo do trabalho e na realidade política do país orientou os agentes sindicais a criar estratégias flexíveis que poderiam alcançar os novos ditames do capital e os interesses gerais das centrais sindicais. As centrais CUT e FS consolidaram tipos específicos de estratégias políticas no plano nacional. Enquanto a CUT embasava seus projetos juntamente com o PT (Partido dos Trabalhadores) - a fim de pressionar o poder central e mobilizar os trabalhadores, principalmente nos setores industriais e de serviços públicos para conquistar espaço nas discussões político-institucionais - logo à frente a FS ocupava um espaço de conformação com as regras do tabuleiro neoliberal e fortalecia sua participação como interlocutor do governo, equilibrando seu peso crítico sobre as instituições oficiais da ordem, usufruindo de situações que a colocasse em vantagem na cena política (CARDOSO, 2003).

A FS nasceu em 1991, período das transformações do caráter produtivo industrial e da crise sindical. A bandeira da central colaborou para efetivar as tendências liberais em destaque no momento, revelando outro aspecto importante

\footnotetext{
7 Segundo o parágrafo único da lei de reconhecimento das centrais sindicais: "Considera-se central sindical, para os efeitos do disposto nesta Lei, a entidade associativa de direito privado composta por organizações sindicais de trabalhadores". (Decreto-Lei n. 11.648, de 31 de março de 2008).

${ }^{8}$ A relevância do reconhecimento legal das centrais sindicais implica o amadurecimento das relações sindicais estabelecidas no Brasil. Entretanto, a formalização da arrecadação sindical demonstra um lado contraproducente das centrais, pela parcela de contribuição repassada aos cofres de sua estrutura.
} 
para o movimento sindical brasileiro. Os interesses da FS possibilitaram um alcance das bases do governo e de lideranças capitalistas, tornando-a instrumento de colaboração com o capital e com a Presidência da República. Contudo, podemos comparar analiticamente a nova central sindical UGT que promove a bandeira do sindicalismo cidadão, ético e inovador com os preceitos difundidos pela FS. Foi fundada em 2007 no Congresso Nacional de Trabalhadores, adensando outras centrais sindicais como a Confederação Geral dos Trabalhadores (CGT), a Social Democracia Sindical (SDS) e a Central Autônoma de Trabalhadores (CAT) ${ }^{9}$. Essa fusão permitiu que antigos membros das organizações, suplantados ao novo corpo sindical, produzissem concepções asseguradas nas raízes do tradicional sindicalismo.

Outro aspecto que aproxima a FS do perfil da UGT é a trajetória de Ricardo Patah, presidente da UGT e do Sindicato dos Comerciários. Patah, em 1991, ocupou o cargo de tesoureiro da FS, central que incorporou interesses capitalistas negociáveis com o Estado e germinou sua história com base no quadro de mudanças sindicais nos anos de 1990, caracterizado pela crise dos sindicatos. É sindicalista pela via da colaboração e não do enfrentamento, fator que influencia a concepção das práticas sindicais na UGT. Esta atualmente representa 730 sindicatos legitimados e mil entidades filiadas cuja base de maior representação abarca o setor de comércio e serviços ${ }^{10}$. Ambas as entidades sindicais compartilham de abordagens semelhantes, razão que questiona a possibilidade da UGT, enquanto nova central sindical, de criar inovações estratégicas em suas práticas cotidianas para modificar a ordem do que já é reproduzido automaticamente.

Já a política da CUT empreendeu uma ofensiva ao sistema de flexibilização das contratações e reavivou a discussão sobre a defesa de políticas sociais que estavam sendo arbitradas pelo governo de Fernando Henrique Cardoso (FHC) (CAR-

\footnotetext{
${ }^{9}$ As propostas da CGT no contexto de reestruturação produtiva priorizaram a manutenção dos postos de trabalho e diminuição do desemprego. A central ressaltou a necessidade de levar os interesses dos sindicatos para questões mais amplas e não apenas ao atendimento de demandas corporativistas da entidade. Para enviesar o desenvolvimento tecnológico como ferramenta de contribuição para sua participação social, a CGT defendeu uma educação baseada nos novos sistemas de produção a fim de atender aos princípios de prática sindical, levando em conta o aparelho público do Estado e questões como a reforma tributária e o melhor desempenho nos gastos públicos (SANTANA, 2000).

10 A União Geral dos Trabalhadores possui base majoritária de representação no setor de comércio e serviços. Por essa razão, suas práticas são interligadas com as estratégias sindicais promovidas pelo sindicato dos comerciários de São Paulo. Esses dados foram obtidos na página virtual da central sindical (www.ugt.org.br).
} 
Doso, 2003). Contudo, ao ganhar espaço político no governo petista de Lula, afastou grupos de militância esquerdista por promover políticas sindicais em desacordo com seus princípios de formação. Dessa forma, houve uma ruptura no interior da CUT, dando origem a duas correntes sindicais políticas: a Conlutas e a Intersindical.

A criação da Conlutas ocorreu no Congresso Nacional dos Trabalhadores em $2006^{11}$. 0 intuito da central é agregar sindicatos, movimentos sociais e representantes populares de origens heterogêneas com o propósito comum de organizar forças para beneficiar os trabalhadores brasileiros, princípio cofundador da CUT nos anos de 1980, central tradicional que encabeçou a trajetória do diretor sindical José Maria12, personagem que contribuiu para fundação do PT e, em 1983, da CUT. Militou nesta última como membro da executiva nacional de 1991 até 2004, quando se desligou da central por discordar das diretrizes, que provocaram um distanciamento da classe trabalhadora após a posse presidencial de Lula. Pela perspectiva de utilizar o sindicalismo como ferramenta para modificar a realidade, o dirigente sindical propôs alternativas que um dia figuraram a central tradicional CUT.

A segunda corrente que rompeu com a CUT, a Intersindical, foi fundada em 2006 na cidade de Campinas. Dividida por grupos de princípios ideológicos diferenciados, a central abarcou frações de militantes que discordaram do formato de sindicato proposto pela Conlutas. No evento de formação reuniu trabalhadores, dirigentes sindicais e movimentos sociais para discutir novos caminhos para o sindicalismo que vão ao encontro do socialismo ${ }^{13}$. Um dos princípios apontados pelo militante da Intersindical e dirigente da Nova Central Sindical (NCS) ${ }^{14}$, Walber

\footnotetext{
11 A Conlutas está em processo de cadastramento de sindicatos para obter reconhecimento legal como central sindical por meio do Ministério do Trabalho.

12 Desde a década de 1970, no ABC paulista, José Maria participou ativamente do processo de redemocratização no Brasil com greves em massa, também foi dirigente do sindicato dos metalúrgicos de Belo Horizonte e diretor da federação democrática dos metalúrgicos de Minas Gerais. Atualmente é dirigente da Conlutas e do sindicato dos metalúrgicos, e ainda se candidatou ao cargo de presidente nas eleições 2010 pelo PSTU (Partido Socialista dos Trabalhadores Unificados).

13 A frente de representação da Intersindical critica o posicionamento de centrais sindicais tradicionais por agirem em conciliação com capitalismo e com o Estado sem favorecer o trabalhador. Dessa forma, sua existência não oficializada no Ministério do Trabalho demonstra a intenção de produzir um sindicalismo não institucionalizado, distante de cúpulas políticas e mais preocupado com o reconhecimento das categorias de trabalhadores. Mas em vista do futuro, se necessário, poderá concordar com o reconhecimento legal para fortalecer a representação dos interesses da base.

${ }^{14}$ A NCST é uma central brasiliense por formação, criada em 2005. Sua composição representa sete confederações, 136 federações, aproximadamente três mil sindicatos e cerca de 12 milhões de trabalhadores filiados em todo o Brasil.
} 
Monteiro ${ }^{15}$, é a necessidade de um desvio ao formato produzido por centrais tradicionais e, com base nos desdobramentos da discussão do mundo do trabalho, criar opções de melhorias para a sociedade. 0 sindicalismo se refaz, por meio de características dominantes que colocam como condição uma relação com o passado, em um ciclo previsto de mudanças em que prevalece a lógica estrutural. Na contemporaneidade suas ações possuem reflexos de curta duração. É com esse ponto de vista que Walber Monteiro destacou as diferenças da Intersindical com as centrais sindicais tradicionais:

[...] pra gente não é importante o reconhecimento do Estado, mas sim o reconhecimento das categorias. Então, a nossa opção, em vez de fazer um esforço de legitimar, legalizar nacionalmente, é fazer um trabalho que é exatamente a discussão do tempo do pró-CUT, de que qualquer instrumento da classe trabalhadora tinha que ter o referendo do trabalhador. A grande questão é que não vemos a necessidade de mais uma central sindical pra fazer o mesmo que as outras sete fazem. Nós temos hoje no Brasil mais de 400 células de trabalho nos sindicatos que a gente representa. A Intersindical, por não ser uma central oficial, pode dialogar com os sindicatos filiados [a outras centrais] que não concordamos com a linha [de atuação]. Nós temos sindicatos hoje, que respondem à Intersindical, que estão na CUT, estão na nova central, estão na UGT. Eu consigo fazer o debate com a categoria, como a gente sempre mencionou há 40 anos no pró-CUT, pra realmente representar, porque senão fica mais do mesmo, o grande problema é que se nós cairmos, a gente recua no mesmo sentido que faz a CUT, por exemplo. 0 problema é de quem a gente representa (entrevista concedida em julho de 2010).

Numa outra visão, Ricardo Patah avaliou alguns aspectos que diferenciam a UGT das centrais sindicais tradicionais, pontuando seus princípios inovadores:

[...] nós somos a única central do Brasil que estamos lutando muito pela questão da resolução da situação dos comerciários. A UGT tem alguns sentimentos que diferenciam de outras centrais, então é uma central sindical que tem tentado fazer com que a voz desses milhões de trabalhadores e trabalhadoras seja sentida em todos os níveis, em especial, no executivo de nosso país. A UGT tem um diferencial interessante porque nós somos plurais, e tanto a CUT quanto a FS tem, por exemplo, uma linha política basicamente de um partido só, e nós achamos que não devemos seguir um partido, nós achamos que os partidos devem estar trabalhando para a sociedade, não pra UGT. A

\footnotetext{
15 Mais conhecido como Magrão, o sindicalista entrevistado relatou o início de sua trajetória sindical no movimento secundarista no final dos anos de 1980 com manifestações de massa incluindo a "fora Collor". Quando foi servidor do Estado, reivindicou um sindicato atuante para o setor público a fim de conquistar direitos trabalhistas, prática da qual as associações assistencialistas não cumpriam. Membro da coordenação nacional da Intersindical e voz dissonante na Nova Central Sindical de Trabalhadores no qual seu sindicato é filiado, o sindicalista e também candidato a deputado estadual nas eleições de 2010 pelo PCB (Partido Comunista Brasileiro) percorre dois paralelos entre entidades sindicais com perfis diferenciados. Ao recriar sentidos para o sindicato com propostas de mobilização esquerdista mediante a Intersindical, e ao colocar em pauta sua opinião sobre as ações da Nova Central, esse personagem consegue dialogar com correntes políticas convergentes e faz com que essas estruturas de sindicalismo confluam nos espaços do discurso.
} 
UGT tem como temas principais as questões da cidadania, por isso que ela é inovadora (entrevista concedida em março de 2010).

Mas, para José Maria, a central sindical não oficializada Conlutas, corresponde aos princípios da CUT dos anos de 1980. Esse resgate pode constituir uma alternativa para o sindicalismo atual:

\begin{abstract}
[...] a Conlutas de fato resgata os princípios de construção da CUT, a ideia de que é necessário transformar a sociedade, e organiza e orienta as formas do cotidiano em defesa do salário, da moradia e do emprego, com base nessa lógica. Ao mesmo tempo, muda a tradição, muda aquilo que são as formas de relações que já estão estabelecidas dentro dos sindicatos e movimentos populares, como uma forma de relação muito ruim, uma relação muito utilitária. 0 que nós queremos com a Conlutas é ter um polo consciente para construir esse processo de resistência, de luta. A direção da Conlutas é constituída por uma coordenação nacional de entidades que se reúnem a cada dois meses. Então a cada reunião da coordenação nacional, todos os sindicatos e movimentos populares que fazem parte da Conlutas mandam seus representantes pra reunião. A direção não tem mandato fixo; a cada reunião, se o sindicato quiser mandar uma pessoa diferente ele manda (entrevista concedida em abril de 2010).
\end{abstract}

Nas novas centrais transparecem a permanência de elementos tradicionais do sindicalismo praticado, cuja tendência fixa um ponto comum entre as novas centrais sindicais: de que todas elas são oriundas de centrais sindicais tradicionais.

\title{
Retratos da crise e os "estilhaços discursivos" do novo sindicalismo
}

A onda de iniciativas tecnológicas projetadas para o século XXI inaugurou escalas elevadas de desafios para o sindicalismo. Grandes centrais como a CUT e a FS foram submetidas ao um redimensionamento das práticas tradicionais. Esse fenômeno lançou luz ao período caracterizado pela crise dos sindicatos, que consistiu em queda das taxas de sindicalização e de greves, crescimento do desemprego, criação de postos informais de trabalho e desenvolvimento do setor de serviços, baixa qualificação na mão de obra para atender exigências do setor tecnológico e crescente individualização nas relações de trabalho. Para além das mudanças produtivas, houve uma profunda alteração dos sentidos de ação sindical em um período adensado por incertezas, conformadas ao projeto neoliberal. Essa realidade impôs novos desafios sindicais para o século XXI, de acordo com Ricardo Patah, presidente da UGT: 
[...] no campo do trabalho, a tecnologia veio para ceifar postos de trabalho e não tivemos tempo para pensar no que estava acontecendo. Pra ter uma ideia, nós tínhamos no Brasil, há uma década, um milhão de bancários, hoje nós temos 400 mil. Na indústria a mesma coisa, e agora se está buscando essas alternativas de tecnologia na área do comercio, que vai ser um desastre. Então nós precisamos qualificar nossos trabalhadores para terem a percepção e sensibilidade de como trabalhar esse novo mundo que estamos vivenciando, esse mundo da tecnologia. Nós queremos, inclusive, valorizar a dimensão de quem nós representamos no comércio e serviços no Brasil (entrevista concedida em março de 2010).

Os temas clássicos abordados pelos sindicatos e suas respectivas centrais sindicais como garantia de emprego e renda mínima, direitos trabalhistas, greves, aumento de salários, negociações coletivas, entre outros, chocaram-se ante o novo tipo de trabalhador predominantemente individualista e autônomo quanto às inúmeras qualificações criadas pelas invenções tecnológicas. 0 "aldeão urbano", termo de Michael Dertouzos (1998), expressou um tipo de trabalhador atuante no mercado de informações; a extensão econômica legitima a tecnologia em função das alterações repercutidas de forma decisiva nas novas práticas que exigem um conhecimento técnico-científico para o desenvolvimento dos negócios. A sociedade da informação invadiu a contemporaneidade, deixando um déficit de produção em escala global.

A consolidação do Novo Sindicalismo refletiu um processo de mudanças no terreno político brasileiro com o surgimento de novos líderes sindicais para defender interesses populares e confrontar com o regime político estabelecido. Com a criação da CUT em 1983, conheceu-se uma nova face dessa realidade despertada pela agitação sindical e pelo desejo democrático. Baseando-se nas análises do professor Iram Jácome Rodrigues (1999), diferente de um passado que previa condições sindicais institucionalizadas, as grandes mobilizações nas fábricas metalúrgicas no ABC, em Diadema e em São Paulo, e o surgimento de representantes sindicais, contribuíram para a construção do perfil desse novo sindicalismo, efetivando um rompimento temporário com o Estado. Da crítica sobre a estrutura sindical nos anos de 1980, o debate que questionou os rumos da práxis sindical efetuada principalmente pela CUT nos anos seguintes foi em relação à própria capacidade de adaptação ativa nesse mesmo modelo corporativo (RoDRIGUES, 1999).

Os signos da política neoliberal debilitaram o propósito de luta de classe do Novo Sindicalismo nos anos de 1980. Na visão de Antonio Cruz (2000), a dimensão 
do período impactou a sociedade por meio da ativação dos sentidos de mobilização coletiva, o discurso das lideranças políticas sindicais estava em consonância com as experiências vivenciadas pelos trabalhadores, fazendo da ação social um código universal. Os componentes da estrutura sindical foram suspensos enquanto o avanço das relações econômicas passou a limitar o poder de decisão no espaço das negociações coletivas e suas diversas tensões de interesse. Daí em diante, os novos padrões de acumulação operaram na dinâmica mundial, afetando o ritmo da população brasileira, prejudicada com os direcionamentos políticos e econômicos do Regime Militar. No intuito de levantar forças políticas apoiadas em movimentos populares, a CUT e o PT conectaram os principais problemas do momento em um discurso homogêneo, que estimulou debates de caráter classista, formando uma grande massa de oposição ao poder central. Nesse espaço, o fenômeno da crise do discurso do novo sindicalismo demonstrou que a desfavorável leitura sindical diante do ritmo imposto pelo choque da transição tecnológica produtiva fragmentou o território de sua autonomia em função da ineficiência discursiva e da própria confusão teórica em definir as situações de conflitos das categorias de trabalho.

Um ponto forte que contribuiu para popularizar os princípios da CUT-PT foi o de mudar o estado de coisas da sociedade. As propostas participavam de uma dimensão ampliada dos problemas sociais que colidiram de frente com as bases da pirâmide social. Mas, após a crise dos sindicatos, houve um abandono do discurso realista e pragmático, distante das condições de trabalho que estavam surgindo, tornando o sindicalismo um instrumento obsoleto.

A mutação do perfil reivindicatório do sindicato causou profundo desconforto no trato das relações coletivas de trabalho e na maioria das abordagens teóricas sobre o tema, expondo a quebra de valores que separavam os interesses materiais da classe trabalhadora. As consequências do capitalismo pós-industrial legitimaram todas as nuanças de seu efeito na prática sindical tradicional. Assim, resta ao sindicato um espaço cada vez mais restrito; a redução das circunstâncias que favoreciam sua expansão passaram a competir com o crescimento do setor de serviços, com individualização profissional, com as quedas de taxa de sindicalização e 
ausência de poder em agregar coletivos de trabalhadores em greves ${ }^{16}$ (RoDRIGUES, 2002).

Na tentativa de resgatar alguns dos princípios fundadores da CUT, José Maria, diretor da Conlutas, promoveu um discurso de resistência ao capitalismo flexível:

[...] todos os setores explorados e oprimidos cabem aqui dentro, e nós queremos em primeiro lugar fortalecer a luta concreta de cada um deles, pois cada um tem suas demandas concretas, seus interesses específicos, mas ao mesmo tempo [queremos] somar essa luta toda numa luta de classe comum contra o capitalismo. Essa opção me obriga aqui na construção da plataforma política, no plano de ação dessa organização [para] que eu dê conta de responder às necessidades e aos interesses de cada segmento. Nosso desafio fundamental é construir uma alternativa de classe no Brasil que possa reorganizar a sociedade em função dos interesses da maioria. Luta concreta cotidiana, que não podemos deixar de travá-la (entrevista concedida em abril de 2010).

A crise do sindicalismo foi superada pela conformação ao sistema econômico dominante projetado para as novas configurações liberais, sobrepondo princípios mercantilizados no campo dos direitos sociais e dissolvendo a autonomia dos grupos e movimento sociais, despolitizando a ação coletiva pela ausência de representatividade. Nesse contexto, de acordo com a análise de Walber Monteiro, diretor da Intersindical e da NCST, o desafio que obriga repensar a ação sindical na atualidade é:

[...] o reconhecimento da classe trabalhadora, que em nossa opinião está desmobilizada. Nós passamos por um momento histórico de desorganização da classe. É pra gente um grande problema quando a classe não se politiza, porque fica aparte de todo debate que se faz; ao não se politizar, nós temos uma influência muito menor de mobilização, fora as grandes situações; não se coloca as pessoas em movimento. 0 Governo Lula desmobilizou a classe; o Governo FHC foi um governo muito terrível, a conjuntura internacional era terrível, mas a classe trabalhadora estava de um lado só, a gente sabia quem era o inimigo. Hoje, o inimigo está camuflado, o maior inimigo, aliás, está no governo e com $80 \%$ de aprovação, é a pessoa que tem leis que mais desorganizou a classe trabalhadora. A gente não faz revolução pela classe, a gente tem que fazer é com ela. Porque ter mandato pra falar a gente até tem, [tem] legitimidade, mas a gente não vai mudar as coisas (entrevista concedida em julho de 2010).

\footnotetext{
16 Leôncio M. Rodrigues, autor do livro $O$ fim do sindicalismo, avaliou um espaço de atuação pouco favorável aos sindicatos, no sentido de converter a lógica de sua natureza reivindicatória para um perfil ligado à dinâmica do mercado. As condições que um dia possibilitaram a participação sindical ativa na sociedade já não correspondem à rotina do trabalhador do século XXI, essa mudança de origem da ação sindical é um dos principais fatores de deslocamento do sindicato com interesses estritamente relacionados em benefício do trabalhador.
} 
O conjunto de forças que atuam no corpo social já construiu um arquétipo para o sindicalismo, fazendo do tempo de sua existência uma bússola sem horizontes pré-determinados. As novas centrais sindicais reinterpretam os mecanismos de sobrevivência de sua natureza representativa e faz do sistema um módulo de resistência aos impulsos de crise, assim como ocorre na economia capitalista, que prevê a crise como parte do processo de desenvolvimento. Nesse caso, propõe-se refletir a crise enquanto marcador da nova realidade social.

\section{Governo Lula e a aquiescência sindical}

Com a chegada de Lula ao Poder Executivo em 2003, a expectativa de uma participação social mais ampla e representativa trouxe à conjuntura nacional outro parâmetro de política institucional. A idealização de projetos garantidores de cidadania e defesa dos trabalhadores focou em um presidente emergido das bases populares que liderou a oposição ao governo de Fernando Henrique Cardoso por meio de um discurso com princípios do Novo Sindicalismo. Numa agenda política complexa, o papel das centrais sindicais no Governo Lula tornou-se proeminente e fundamental para avivar a participação dos pequenos núcleos sindicais, com intuito de atualizar a agenda do desenvolvimento econômico produtivo do país.

O desempenho positivo de setores da tecnologia e prestação de serviços alterou a dinâmica do mercado, descaracterizando o perfil de empregabilidade dos brasileiros, para atingir uma nova dinâmica do ponto de vista qualitativo. A predominância de uma escala de emprego foi substituída gradualmente pelo surgimento de outros profissionais adequados às demandas da nova realidade, fato que subtraiu a utilidade dos tipos de contratos previstos na legislação trabalhista brasileira. Os temas abordados como desregulamentação do trabalho, redução do número de conflitos com empregador, criação de novos postos de emprego relacionados aos setores em expansão, entre outros, estiveram presentes na agenda de discussões da base governamental lulista, fator que ofereceu um viés sindicalista de forte envolvimento macropolítico. O Fórum Nacional do Trabalho (FNT), criado em 2003, ilustrou um balanço sobre as primeiras ações do Governo Lula, que, den- 
tre outros aspectos, imprimiu na sociedade a decadência da ideologia esquerdista e um processo de torpor do movimento sindical (ALMEIDA, 2007).

A gestão de Lula, que também mencionou a reforma trabalhista e sindical como plano de governo, demonstrou no FNT intenções de caráter conciliatório com os representantes da esfera econômica e política que ali participaram, sucedendo uma propagação de órgãos e comissões relacionados aos interesses das empresas, centrais sindicais e Estado. Como pauta do dia, a possibilidade da reforma sindical destacou a utilidade instrumental do reconhecimento das centrais sindicais enquanto amortecedor das relações entre capital e trabalho.

Essa nova formatação da estrutura do Estado transferiu grande parcela dos representantes sindicais para postos de confiança no governo federal. A inserção dos membros da instituição cutista, ligada ao PT, na burocracia política formou uma nova elite sindical, indicando uma revalorização da percepção sobre o trabalho e dos sindicatos nesse momento. As centrais sindicais no FNT responderam pela coordenação majoritária da CUT, mas tal participação não possibilitou avanços para construção de alternativas no movimento sindical. Os representantes insistiram em um modelo verticalizado, sem romper com a tríade modular entre capital, trabalho e Estado. Os caminhos para uma regulamentação mais justa em beneficio dos trabalhadores tiveram efeito nocivo no peso das mudanças estruturais do trabalho (ALMEIDA, 2007).

Dentro do intenso fluxo de forças políticas, Lula assumiu o papel de árbitro das questões nacionais, sobretudo nas relações de trabalho nas quais se incluíram as novas centrais sindicais. Das expectativas de um espaço mais aberto aos interesses dos trabalhadores, Lula cooperou para uma tendência sindical cada vez mais incorporada na máquina de Estado. 0 reflexo da cúpula sindical na macroestrutura possibilitou o fortalecimento do sindicalismo por meio de interferências governamentais e não da participação popular. De oposição, o Governo Lula passou a usar as peças do jogo capitalista para suas estratégias políticas e sindicais, paralisando os instrumentos de mobilização social que fez de sua matéria de reivindicação uma ramificação da estrutura.

Como forma para repensar as novas centrais no campo da política institucional, a elaboração dos projetos futuros da UGT tem o intuito de ampliar sua par- 
ticipação representativa na estrutura do Estado. Como interlocutora do governo, ela representa o caráter conciliador com os projetos do governo junto às necessidades da burguesia:

[...] no que tange a essas grandes situações e questões, nenhuma central sozinha tem qualquer tipo de proposta que possa ser efetivada. Aí é uma necessidade das centrais estarem unidas nesse sentido, e no que tange a crise a unidade das centrais também ajudou. A UGT tem como perspectiva uma participação firme na política, por intermédio dos seus representados eleitos, porque na casa das leis nós vamos conseguir no mínimo fazer com que não haja definições contrárias à classe trabalhadora. A meu ver, hoje, o Lula está consagrado de forma internacional, no campo sindical, não há dúvida, pela sua origem; nunca tivemos um presidente que ouvisse tanto a atividade sindical e social. Colocando dentro do seu conselho vários dirigentes sindicais (Ricardo Patah em entrevista concedida em março de 2010).

O decréscimo da participação coletiva e o esvaziamento das práticas sindicais no cotidiano demonstram a distância da sociedade brasileira com os assuntos de interesse público. Os mecanismos de consumo em massa desmobilizaram a sociedade para interesses de bem coletivo, esse sintoma refletiu uma dependência profunda com as propostas de caráter assistencialista que não preveem a existência de uma organização social autônoma. A despolitização da população distanciou os interesses públicos das metas promovidas por órgãos de representação da sociedade civil. Os sindicatos estão programados principalmente para atuar com o empresariado e o governo, agregando benefícios para a cúpula de poder. Insatisfeito, o trabalhador não reconhece o sindicato como entidade de defesa de seus interesses e não se engaja nas mobilizações sindicais, por desacreditar na capacidade de negociação sindical reivindicatória. Foi nessa perspectiva que a Conlutas verificou a necessidade de participação popular ativa para defesa de interesses das classes em desacordo com os ganhos econômicos da burguesia. Na fala de José Maria:

[...] não pode ser que os projetos que se apresentam sejam da Dilma ou do Serra; a esquerda brasileira, a esquerda socialista, tem que apresentar uma candidatura capaz de expressar esse projeto, que seja no processo eleitoral uma expressão das lutas e que use o processo eleitoral para promover as lutas. A Conlutas não apresenta candidaturas, ela é uma organização sindical popular, ela é autônoma em relação aos partidos, não devemos indicar diretamente alguma candidatura justamente para preservar o respeito à liberdade política. Mas os partidos nos quais militamos devem apresentar; o PSTU vai apresentar uma candidatura à Presidência da República (entrevista concedida em abril de 2010). 
Mas a posição de Walber Monteiro quanto à participação da Intersindical em negócios do Estado está vinculada ao sentido de defesa dos trabalhadores, potencializada pela estrutura partidária:

[...] hoje oficialmente na Intersindical estamos em unidade classista, e alguns são do PCB. Nem todo mundo da unidade classista é do PCB, mas todo mundo concorda com a linha sindical de unidade, então a gente milita junto, tal alternativa sindical é a socialista. Por exemplo, eu sou candidato a deputado, ao contrário do que faz o deputado, nossa campanha está disponível para o movimento. Partido comunista hoje tem que estar à disposição dos movimentos (entrevista concedida em julho de 2010).

As relações entre capital e produção foram intensificadas pelo processo de conversão de interesses de uma minoria para um largo conjunto de trabalhadores, que passou a compartilhar princípios sustentados na prática do consumo incentivada por programas do Governo Lula. A participação ativa dos trabalhadores na ampliação do mercado contribuiu como instrumento de desmobilização sindical. De acordo com André Singer (2009), o Governo de Lula lançou um processo de suspensão do programa de esquerda, adotando estratégias das quais atendiam ao pacto capitalista. Contudo, os diversos interesses das classes e elites políticas se acomodaram dentro da estrutura do Estado. Lula reconfigurou a participação política de oposição e atraiu para o plano discursivo de campanha, no segundo mandato, a parte mais conservadora da sociedade brasileira, deixando uma parcela de centro (representada pela classe média) distante de sua atenção. Tal fenômeno implicou um processo de realinhamento ${ }^{17}$ que confundiu a natureza da esquerda e da direita, afinal essas definições não compartilhavam mais uma divisão políticoideológica. Com as oposições arbitradas pelo Estado e com um sindicalismo cada vez mais suscetível aos efeitos da financeirização, a arqueologia institucional do Governo Lula conseguiu abarcar blocos políticos antagônicos, unindo mudanças políticas na ordem do aparelho estatal e diminuindo a propensão ao conflito social. É nesse contexto que o sindicalismo se tornou instrumento manipulado pelas estratégias neoliberais adaptadas ao fenômeno do lulismo, que realizou uma junção

\footnotetext{
17 Para Singer (2009), o fenômeno de realinhamento eleitoral ocorreu em 2006, no segundo mandato de Lula, fator que evidenciou mudanças na sociedade brasileira, principalmente no aspecto econômico domiciliar. A hipótese do autor refere-se às classes pobres concentradas no Nordeste do Brasil (região mais propensa ao lulismo), que representam a condição do subproletariado. Esse substrato da sociedade se manteve fiel ao Lula mesmo com melhorias na renda e acréscimos ao poder de compra, elementos que se enquadram em outra categoria da pirâmide social.
} 
de elementos da esquerda e da direita, trazendo um novo perfil ideológico para as tensões políticas produzidas na arena social.

Por outro ângulo, enquanto a economia global passava por uma crise impetuosa em 2008, demonstrando um fortalecimento do Brasil em relação à intensa reação negativa de outros países, a política social de Lula investiu em programas populares de transferência de renda, controlando os índices de desenvolvimento populacional e promovendo uma ampliação aos direitos de cidadania. Na política institucional firmaram-se alianças partidárias que salientaram contradições ideológicas no aparelho estatal. Por fim, o movimento sindical foi beneficiado pelo amplo espaço de participação na máquina do Poder Executivo, para efetivar um diálogo permanente entre os poderes regulares na arena política. Nesse sentido, as reformas sindicais e trabalhistas do Governo Lula surtiram frágeis efeitos em sua proposta inicial. 0 pragmatismo lulista resgatou o fio condutor do processo de crescimento econômico do governo anterior, diminuindo as expectativas de mudanças basilares na sociedade brasileira (LADOSKI, 2009).

A despeito de um presidente que criticou as políticas neoliberais, o programa promovido por Lula contemporiza a realidade nacional advinda do processo de ampliação do mercado financeiro nos anos de 1990. 0 capitalismo sindicalista conciliador, unidade conceitual emprestada de Wallace dos Santos Moraes (2009), oferece-nos uma compreensão sobre a relação que une interesses dos sindicalistas com o conjunto de ministérios e instituições de representação do Poder Executivo. Esse fator recai na permanência das estruturas tradicionais corporativas influenciadas pelo capitalismo, portanto, na manutenção de práticas que acionam a relação de interesses sindicais mais amplos com o capital. Desse modo, o sindicalismo passou a operar seu próprio interesse no plano das relações políticas institucionais, combinando estratégias capitalistas de negociação aberta pautadas pelo empresariado e por programas políticos do Estado. Isso imprimiu ao sindicato um papel de desmobilizar instâncias sindicais de enfrentamento e de difundir uma prática mecânica de representação dos trabalhadores. 
A transitoriedade do sindicato-movimento para sindicalismo-conciliador contribuiu para a formação do sindicato-empresa ${ }^{18}$. Esse fenômeno ofertou uma racionalidade capitalista no cotidiano dos sindicatos e criou meios de profissionalizar cargos de sindicalistas. Assim, o representante sindical incorporou a estrutura empresarial em suas tarefas e conquistou status de nível gerencial, distante dos conflitos e contestações trabalhistas. Com isso, os problemas da classe tornaram-se um objeto de manuseio operacional; o filiado se converteu em cliente subserviente aos estímulos da esfera do consumo e da mercantilização dos próprios direitos (Bernardo; Pereira, 2008).

A exploração dos meios de obtenção de lucro contribuiu para o sistema do sindicato rentável, por meio de negociações baseadas em contribuições dos trabalhadores. 0 capitalismo sindical tem como propósito manipular a oferta de ações do mercado corporativo, retirando do salário do trabalhador uma fração para ser investida em ativos de sua empregadora. Diante da novidade que se lançou como alternativa para avivar a participação sindical nas questões do governo e da economia, muitos representantes sindicais fundaram um novo grupo no mercado de ações, compartilhando as estratégias financeiras por meio de arrecadação dos fundos de pensão na prática sindical cotidiana. Centrais sindicais como a CUT, a FS e também a CGT passaram a gerenciar a massa de investimentos cuja parcela retirada do salário é convertida em políticas compensatórias para o futuro do trabalhador. Essa ferramenta sindical se tornou um importante recurso atualizado com os fluxos do capital corporativo (MARTINS, 2007).

\section{Considerações Finais}

A coleção de ideias e falas expostas ao longo deste artigo nos possibilitou uma mediação entre a ação do tempo no sindicalismo brasileiro e suas principais

\footnotetext{
180 sindicato-empresa corresponde à inversão do órgão de representação dos trabalhadores em instrumento de colaboração com os interesses corporativos. Esse tipo de sindicalismo é reconhecido nas práticas atuais dos sindicatos envolvidos em negociações que se restringem ao campo de defesa dos trabalhadores. A acumulação do capital sindical tornou-se a principal atividade exercida pelos dirigentes sindicais, essa prática da obtenção de lucro por meio da satisfação das necessidades da burguesia empresarial viabilizou um sindicalismo cooperador com o regime de mercado e inativo ante sua capacidade de acolher as demandas dos trabalhadores (BERnardo; PEREIRA, 2008).
} 
diretrizes adensadas no interior do Estado e no avanço das práticas neoliberais. 0 peso da trajetória corporativista na formação do sindicato-instituição e os parâmetros de continuísmo e inovação como fator de comparação entre as centrais sindicais tradicionais e as novas centrais sindicais nos ofereceu uma breve compreensão sobre os meios de representação do sistema disponíveis aos trabalhadores atualmente.

A UGT manteve o caráter estrutural com alterações de curto prazo na sua agenda conforme as demandas pautadas na ordem do dia. 0 contraste da nova central sindical UGT com a FS ou com a CUT - protagonista da ruptura com a cidadania regulada do Estado -, conciliadora dos interesses trabalhistas com o mercado capitalista, alcançou práticas que mantiveram o molde sindical em outra dimensão temporal, incorporando novos elementos de representação sem colocar em risco a estrutura tradicional. A Conlutas, ao romper com a CUT, transformou-se em outra central sindical com intuito de resgatar os princípios cutistas de fundação, a fim de reavivar a participação ativa das classes e dos movimentos sociais. Já a Intersindical propôs uma ruptura com o modelo de sindicato vigente, com o propósito de contrariar a herança estrutural que cerceou a participação dos trabalhadores. Contudo não recusou o fato de no futuro ser necessário o reconhecimento institucional.

A Conlutas e a Intersindical apresentaram um propósito mais ativo e aproximado com os trabalhadores e movimentos populares a fim de retomar o espírito politizado nas ações sindicais. Sem inaugurar uma nova fase para a política sindical, as novas centrais ainda dão passos tímidos em relação ao sindicalismo praticado atualmente, fixando sua participação em questões onde o poder de decisão compete ao peso do governo e das exigências do empresariado. Uma possível inversão do quadro sindical brasileiro, passando de mero expectador para coadjuvante na defesa dos interesses do trabalhador, está longe de ser visualizada como um fenômeno sentido em todas as esferas sociais.

A relação com o continuísmo ainda domina as práticas sindicais do presente promovidas pelas novas centrais. Sendo assim, a trajetória sindical se constitui num acúmulo de ruínas, como uma fragmentação em função das mudanças do tempo. Os novos rumos para o sindicalismo pedem que a instituição sindicato re- 
pense suas ações representativas e faça novos contornos condizentes com o mundo de agora. De qualquer forma, os fatores que englobam esta jornada de estudos estão distantes de situar uma conclusão definitiva sobre o papel das novas centrais sindicais na sociedade contemporânea. Esta etapa de estudos impede resultados acabados nessa infinita teia de discussão.

\section{Referências}

AlmeIDA, G. R. (2007). "O Governo Lula, o Fórum Nacional do Trabalho e a Reforma Sindical”. Revista Katál, Florianópolis, vol. 10, n. 1, p. 54-64.

Alves, G. (2000). “Do 'novo sindicalismo' a 'concertação social': Ascensão (e crise) do sindicalismo no Brasil (1978-1998)". Revista de Sociologia e Política, Curitiba, vol. 15, p. 111-124. Disponível em: <www.scielo.br/pdf/rsocp/n15/a08n15.pdf $>$. Acesso em fev. 2010.

Bernardo, J.; Pereira, L. (2008). Capitalismo sindical. São Paulo, Xamã.

Cardoso, A. M. (2003). A década neoliberal e a crise dos sindicatos no Brasil. São Paulo, Boitempo.

CASTORIADIS, C. (1992). O mundo fragmentado: as encruzilhadas do labirinto. 3.ed. Rio de Janeiro, Paz e Terra.

CRUZ, A. (2000). A janela estilhaçada: a crise do discurso do novo sindicalismo. Rio de Janeiro, Vozes.

Dertouzos, M. L. (1998). O que será? Como o novo mundo da informação transformará nossas vidas. São Paulo, Companhia das Letras.

KumAR, K.; JUnGMANN, R. (1997). Da sociedade pós-industrial à pós-moderna: novas teorias sobre o mundo contemporâneo. Rio de Janeiro, Zahar.

LAdoski, M. H. G. (2009). A CUT no Governo Lula: Da defesa da "liberdade e autonomia" à reforma sindical inconclusa. Tese (Doutorado em Ciência Política) - Faculdade de Filosofia, Letras e Ciências Humanas, Universidade de São Paulo, São Paulo.

MARTins, C. E. (2007). “O Brasil e a dimensão econômico-social do Governo Lula: resultados e perspectivas”. Revista Katál, Florianópolis, vol. 10, n. 1, p. 35-43.

Moraes, W. S. (2009). "Capitalismo sindicalista de conciliação" e "capitalismo de las calles": os casos de Brasil e Venezuela no pós-neoliberalismo na América Latina. Tese (Doutorado em Ciência Política) - Instituto Universitário de Pesquisas do Rio de Janeiro, Rio de Janeiro. 
NUNES, E. (2003). A gramática política do Brasil: clientelismo e insulamento burocrático. 3. ed. Rio de Janeiro, Jorge Zahar.

Rodrigues, I. J. (org.). (1999). O novo sindicalismo: vinte anos depois. Petrópolis, Vozes.

Rodrigues, J. A. R. (1968). Sindicato e desenvolvimento no Brasil. 2. ed. São Paulo, Símbolo.

Rodrigues, L. M. (2002). Destino do sindicalismo. 2. ed. São Paulo, EduSP.

SANTANA, M. A. (2000). "As centrais sindicais brasileiras e a reestruturação produtiva: análises e propostas". Sociologias, Porto Alegre, ano 2, n. 4. Disponível em: $<$ http://www.scielo.br/scielo.php?script=sci arttext\&pid=S1517-4522200000020 0008\&lang=pt>. Acesso em: jun. 2009.

Santana, M. A.; Ramalho, J. R. (orgs.). (2003). Além da fábrica: trabalhadores, sindicatos e a nova questão social. São Paulo, Boitempo.

SEnNETt, R. (2008). A corrosão do caráter: consequências pessoais do trabalho no novo capitalismo. 13. ed. Rio de Janeiro, Record.

Singer, A. (2009). "Raízes sociais e ideológicas do lulismo". Novos Estudos Cebrap. São Paulo, n. 85, p. 83-102. Disponível em: <www.scielo.br/scielo.php?script= sci abstract\&pid=S0101-33002009000300004\&lng=en\&nrm=iso\&tlng=pt $>$. Acesso em: ago. 2010.

Recebido em janeiro/2011

Aprovado em junho/2011 